\title{
Risk factors in the onset of neck/shoulder pain in a prospective study of workers in industrial and service companies
}

\author{
J H Andersen, A Kaergaard, S Mikkelsen, U F Jensen, P Frost, J P Bonde, N Fallentin, \\ J F Thomsen
}

See end of article for authors' affiliations

Correspondence to: DrJ H Andersen, Department of Occupational Medicine, Herning Hospital, GI. Landevej 61, DK-7400 Herning, Denmark; hecjha@ringamt.dk

Accepted 6 August 2002

\begin{abstract}
Aims: To quantify the relative contribution of work related physical factors, psychosocial workplace factors, and individual factors and aspects of somatisation to the onset of neck/shoulder pain.

Methods: Four year prospective cohort study of workers from industrial and service companies in Denmark. Participants were 3123 workers, previously enrolled in a cross sectional study, where objective measurement of physical workplace factors was used. Eligible participants were followed on three subsequent occasions with approximately one year intervals. Outcomes of interest were: new onset of neck/shoulder pain (symptom cases); and neck/shoulder pain with pressure tenderness in the muscles of the neck/shoulder region (clinical cases).

Results: During follow up, 636 (14.1\%) participants reported neck/shoulder pain of new onset; among these, $82(1.7 \%)$ also had clinical signs of substantial muscle tenderness. High shoulder repetition was related to being a future symptom case, and a future clinical case. Repetition was strongly intercorrelated with other physical measures. High job demands were associated with future status as a symptom case, and as a clinical case. A high level of distress predicted subsequent neck/shoulder pain, and neck/shoulder pain with pressure tenderness.

Conclusions: High levels of distress, and physical and psychosocial workplace factors are predictors of onset of pain in the neck and/or shoulders, particularly pain with pressure tenderness in the muscles.
\end{abstract}

$\mathrm{N}$ eck/shoulder pain is frequently reported among workers with repetitive manual tasks as well as among some service workers. ${ }^{12}$ The aetiology is largely unknown, and most studies so far are cross sectional. ${ }^{3}$ Prospective studies have been conducted, and physical and

\section{Main messages}

- High physical workload was associated with onset of pain in the neck and/or shoulders, particularly pain with pressure tenderness.

- High job demands and low job control were independently associated with the onset of symptoms.

- Level of distress predicts future symptoms and clinical signs from the neck and/or shoulders.

- Women and men had an equal risk for new pain in the neck and/or shoulders, but women had a higher risk for future clinical case status.

- A general low pain pressure threshold did not predict future pressure tenderness in the neck and/or shoulders.

\section{Policy implications}

- A concerted action against physical workplace factors could probably prevent more serious neck and/or shoulder pain.

- Outsourcing of high strain jobs from the western countries calls for cooperation in research on musculoskeletal disorders.

- Further research in the origin of musculoskeletal problems would benefit from the inclusion of sociological and cultural factors. psychosocial workplace factors such as neck flexion, sitting, quantitative job demands, and coworker support have been found to be risk factors for neck pain in a recent study. ${ }^{4}$ Physical work with a heavy load, awkward postures, and mental stress were related to one-year incidence of shoulder pain. ${ }^{5}$ The multifactorial and multidimensional nature of musculoskeletal pain has been the subject of several studies, which have found that psychological distress and other somatic symptoms are related to unspecific pain complaints from the neck and upper extremity. ${ }^{7}$

We aimed to determine the contribution of: (a) physical workplace factors, (b) psychosocial workplace factors, and (c) individual factors and symptom reporting to the onset of new neck/shoulder pain and neck/shoulder pain with pressure tenderness.

\section{METHODS}

The study was conducted as a four year prospective cohort study, with yearly assessment of exposures in the workplace and simultaneous questionnaire screening and clinical examinations; fig 1 illustrates the total flow in the study.

\section{Recruitment}

The study population comprised 3123 workers from industrial and service sector settings, enrolled in 1994 and 1995. Three quarters of the population had mainly repetitive job tasks; a quarter had more varied jobs and served as a reference group. All workers included were unskilled blue collar or white collar

Abbreviations: $\mathrm{Cl}$, confidence interval; $\mathrm{OR}$, odds ratio 


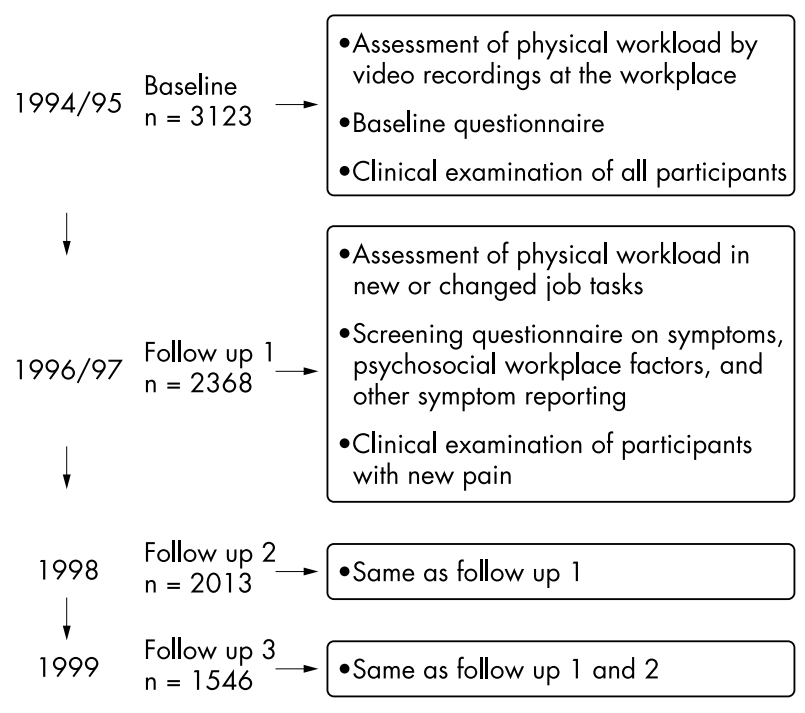

Figure 1 Summary of design of follow up study of neck/shoulder pain among workers in industrial and service companies.

workers; the reference group did not differ from the group with repetitive work on educational level or salary.

The workplaces included four food processing companies, three textile plants, seven other manufacturing, and five service companies. Detailed description of the recruitment and the industries has been reported elsewhere. ${ }^{8}$

\section{Questionnaire}

All participants received a mailed questionnaire at baseline, and underwent a clinical examination at the workplace, focusing on clinical signs from the neck and upper extremities, including pressure tenderness in the following muscles: upper neck muscle, trapezius, supra-and infraspinatus. ${ }^{9}$ The pain pressure threshold in the lower extremities was recorded by a pressure algometer, ${ }^{8}$ and based on the 25 th centile, the participants within the lowest pressure threshold were classified as having an overall low pain pressure threshold. Measures on height and weight were obtained and the BMI calculated as $\mathrm{kg} / \mathrm{m}^{2}$.

The questionnaire contained information on: (a) the psychosocial workplace factors job demands, job control, and social support from the job content questionnaire ${ }^{10}$; (b) the personality trait of "intrinsic effort" from Siegrist's effortreward model, where the 29 items were summed to form an index and dichotomised into high versus low intrinsic effort on the basis of the 25th centile for range of scores for this measure $^{11}$; and (c) reporting of physical, emotional, and cognitive symptoms from the stress profile questionnaire developed by Setterlind. ${ }^{12}$ Eighteen questions were summed to an overall standardised distress score ranging from 0 to 12 . Based on the tertile values across this scale, three levels were created: zero for no distress ( 0 on the scale), one for minor distress ( 0.5 to 2 on the scale), and high level of distress (>2 to 12 on the scale).

Leisure time activity was categorised into "none or light physical activity" (no or light physical activity for less than two hours/week or light activity for two to four hours/week), and "physically active" (light physical activity for more than four hours/week, or two to four hours with hard physical activity, or hard physical activity for more than four hours/week).

\section{Follow up}

At each of three follow up rounds, with approximately one year intervals, a screening questionnaire was posted to the participants to obtain information on pain status, self reported
Table 1 Number (percentage) of participants with new neck/shoulder pain (symptom cases) and new neck/shoulder pain with pressure tenderness (clinical cases)

\begin{tabular}{lll}
\hline $\begin{array}{l}\text { Follow up } \\
\text { round }\end{array}$ & $\begin{array}{l}\text { Symptom cases/ } \\
\text { participants at risk* }\end{array}$ & $\begin{array}{l}\text { Clinical cases/ } \\
\text { participants at risk }\end{array}$ \\
\hline 1 & $266 / 1964(13.5)$ & $34 / 1869(1.8)$ \\
2 & $227 / 1538(14.8)$ & $28 / 1634(1.7)$ \\
3 & $143 / 1011(14.1)$ & $20 / 1244(1.6)$ \\
Total & $636 / 4513(14.1)$ & $82 / 4747(1.7)$ \\
\hline *Participants without earlier case status.
\end{tabular}

psychosocial workplace factors, and other symptoms of distress as described above.

The pain status for both neck and right shoulder region was measured by a numeric box complaint scale from 0 (no complaints at all) to 9 (pain as bad as could be), indicating respectively: severity of pain at worst, level of average pain within the past three months, severity of impairment in daily activities within the past three months due to neck or shoulder pain, and level of average pain within the past seven days. ${ }^{13}$ The scores were summed, giving a possible range of 0 to 36 for each region $($ Cronbach's alpha $=0.93) .{ }^{13}$

An incident case of newly developed pain (symptom case) was defined by a symptom score of less than 12 at baseline and an increase of 12 score values from the neck or right shoulder during follow up. This case definition was based partly on results from a pilot study, ${ }^{13}$ and on rather arbitrary intentions to capture something more serious than fluctuating acute pain episodes. Participants who fulfilled these criteria received a follow up clinical examination. If the participants had indisputable/severe palpation tenderness in the neck muscles or right upper trapezius border, and in the right supra- or infraspinatus muscle, they fulfilled the criteria for neck/ shoulder pain with pressure tenderness (clinical case). ${ }^{8}$ Palpation tenderness was scored on a scale of 0 to 3 and dichotomised into indisputable/severe palpation tenderness (score 2 or 3 ), with withdrawal or jump sign at the palpation, and no or minor palpation tenderness (score 0 or 1 ).

\section{Work related physical factors}

The physical workplace factors were assessed at baseline by a task based strategy of exposure assessment using a real time video based method, which has been described earlier. ${ }^{14}$ There were four steps in the assessment. Firstly, ergonomists visited the 19 company sites and work tasks were classified as either repetitive or control tasks. A repetitive task was one that involved continuous repetitive hand or arm movements. A control task was characterised by varied job tasks. Examples of repetitive task groups are deboning ham, sewing machine work, deboning poultry, packing, continuous data entering, shop cashier, and manual machine feeding. Non-repetitive or control tasks included varied office work, supervision of machines, different kinds of maintenance work, or internal transportation.

Secondly, repetitive tasks with comparable levels of physical exposure - that is, same level of repetition, force, neck flexion, and lack of shoulder recovery time, were aggregated. On this basis five to six task groups were established on each working site, giving a total of 103 grouped tasks.

Thirdly, between one and seven workers in each of the 103 task groups were videotaped from three camera angles for at least 10 working cycles or for a minimum period of 10-15 minutes. The (a) number of shoulder movements/minute, (b) percentage of time with neck flexion more than $20^{\circ}$, (c) percentage of cycle time spent with no upper arm support or rest for more than two seconds (lack of shoulder recovery time), and (d) force requirements ${ }^{15}$ subjectively assessed and 
computed by the observer using five point ordinal scales (zero to four), relative to maximum voluntary contraction, were quantified based on repeated reviews of the video recordings. Each of the 103 repetitive task groups was assigned the median value for the measured neck and shoulder exposures.

The final step involved allocating time weighted exposure measures to participants on the basis of self reported task distribution during a normal week of 37 hours. Exposure measure was calculated by summing the products of task group exposure medians (level) and proportion of time (relative to a normal working week of 37 hours) spent per week in up to five task groups $\left(\right.$ time $\left._{\text {rel }}\right)$-that is, time weighted exposure $=$ $\sum$ (up to five tasks) time $\mathrm{rel}_{\mathrm{rel}} \times$ level. The values for each exposure were divided into three levels on the basis of score distributions: the reference group was assigned the value of 0 , and the repetitive group was assigned 1 (low) or 2 (high): repetitivity (1-15 movements per minute/16-40 movements per minute, force ( $<10 \%$ of $\mathrm{MVC} / \geqslant 10 \%$ of MVC), neck flexion $>20^{\circ}(<66 \%$ of time $/ \geqslant 66 \%$ of time), and lack of recovery time $(<80 \%$ of time $) \geqslant 80 \%$ of time).

\section{Analysis}

Two outcomes were of interest. Participants with pain scores sufficiently greater than the preceding round, as described above, were included as symptom cases. Participants not fulfilling clinical criteria at baseline were included as incident clinical cases when they fulfilled criteria as a symptom case and clinical case criteria in one of the follow up rounds.

The risk of developing pain and the defined clinical disorder was calculated with a logistic regression technique equivalent to discrete survival analysis. ${ }^{16}$ The number of follow up rounds taken to develop the outcome was analysed by logistic regression on the total number of observed follow up rounds. Observations were right censored when the criterion for the outcome became positive; table 1 shows participants at risk for either of the two outcomes. In the analyses of risk factors we applied models with time varying measures of observed and perceived workplace factors. In all analyses we used a time lagged function to link the outcomes with exposure characteristics on job demands, job control, social support, and level of other symptom reporting (distress) from the preceding round of follow up to diminish bias from simultaneous reporting of exposure and outcome. In the final, combined regression model the values ( 0 to 2 ) for the four physical exposure variables were summed up to an overall index ranging from 0 to 8 , and further divided into low combined exposure $(\leqslant 4)$, medium exposure (5-6 on index), and high exposure (7-8 on index). All determinants remained in the models whatever the magnitude or significance of effect.

\section{RESULTS}

The baseline cohort of 3123 workers was more than halved to $1546(49.5 \%)$ in the study period, which lasted almost four years. The drop out was not related to exposure or musculoskeletal symptoms or disorders at baseline. The percentage with monotonous, repetitive work at baseline was $75 \%$, and $68 \%$ at third follow up. We have earlier reported a baseline prevalence on $6.2 \%$ of neck/shoulder pain with pressure tenderness, ${ }^{8}$ and the prevalence among the 1546 participants at the end of follow up was $6.3 \%$. Drop out was strongly related to young age, and to companies moving their production to Eastern Europe.

The average incidence of new neck/shoulder pain during follow up was $14.1 \%$, and for neck/shoulder pain with pressure tenderness the average incidence was $1.7 \%$ (table 1 ).

\section{Risk factors}

\section{Physical workplace factors}

Repetitive movements of the shoulder were the strongest physical risk factor for future pain, and even more for being a future clinical case (adjusted OR 3.0, 95\% CI 1.5 to 5.8; table 2 ). Workers having job tasks where the neck is flexed more than $20^{\circ}$ for more than two thirds of their working time had an increased odds of being a clinical case (OR 2.6, 95\% CI 1.3 to 5.1). We further examined whether greater time spent with the neck flexed more than $20^{\circ}$ was more related to neck pain than to pain localised primarily to the shoulder. The crude odds ratio for onset of neck pain for participants working with the neck flexed for more than two thirds of their working time (OR 1.6, 95\% CI 1.2 to 2.1), and for onset of shoulder pain (OR $1.8,95 \%$ CI 1.4 to 2.3 ), were equal, and at the same level as for our neck/shoulder symptom case, which had an odds ratio of 1.6 (table 2). In general, risk estimates for being a future symptom case and a future clinical case had the same directions, but odds ratios for clinical case status were $65-100 \%$ higher than for being a symptom case. For those with highly repetitive work, the odds ratios for being a future clinical case increased when either a high percentage of time with neck flexion or a low recovery time was present. This trend persisted even without the reference group, indicating an internal exposure-response relation among workers with repetitive work (table 3 ).

\section{Psychosocial workplace factors}

High job demands and low job control were independently associated with the onset of symptoms and future clinical cases. Low social support was not significantly associated with either of the two outcomes (table 4). We found no significant contribution by including the interaction term for job demands and job control or social support.

\section{Combined regression model}

The four physical exposure values turned out to be highly correlated with correlation coefficients between 0.3 and 0.5 , and data for combined physical exposure, job demands, gender, low pain pressure threshold, and level of distress were entered as covariates in a logistic regression model with either onset of symptoms and future clinical cases as outcomes. High physical exposure was a risk factor for symptom cases (OR 1.5, 95\% CI 1.2 to 1.9 ) and for clinical cases (OR 3.2, 95\% CI 1.6 to 6.6; table 5). High job demands stayed in both the models, whereas being a woman only revealed an increased risk for being a future clinical case. Low pain pressure threshold at baseline was a minor risk factor for symptom cases, but not for clinical cases. Level of distress in the follow up round preceding case status showed an exposure-response relation between level of distress and incidence of new symptoms and clinical case status (table 5).

\section{DISCUSSION}

Incidence of neck/shoulder pain and pain in combination with clinical signs of pressure tenderness, was independently related to work related physical factors, high job demands, and to precedent distress. Low pain pressure threshold predicted symptoms but not future clinical status, which was in contradiction to our findings in the baseline of this population. ${ }^{8}$ This finding indicates that the cross sectional association could be caused by central sensitisation and spreading of localised pain. Women were at higher risk of being a clinical case, but not a symptom case. Personality traits measured by Siegrist's intrinsic effort were not related to future pain or clinical signs. The risk estimates for onset of neck/shoulder pain with pressure tenderness were higher for all physical risk factors in this follow up analysis than in the same analysis at the cross sectional level.

Despite $50 \%$ drop out in four years of this study, baseline characteristics on exposures and the outcomes under study were quite similar among the participants who dropped out and among those who were successfully followed up. Three textile companies outsourced their production, other 
Table 2 Physical risk factors for onset of neck/shoulder pain (symptom cases), and neck/shoulder pain with pressure tenderness (clinical cases) among industrial and service workers

\begin{tabular}{|c|c|c|c|c|c|c|c|c|}
\hline \multirow[b]{2}{*}{ Physical risk factor } & \multicolumn{4}{|c|}{ Symptom cases } & \multicolumn{4}{|c|}{ Clinical cases } \\
\hline & $\mathrm{n}$ & Cases & $\mathrm{OR}_{\text {crude }}^{*}$ & $\mathrm{OR}_{\mathrm{adi}} \dagger(95 \% \mathrm{Cl})$ & $\mathrm{n}$ & Cases & $\mathrm{OR}_{\text {crude }}$ & $\mathrm{OR}_{\mathrm{adi}} \dagger(95 \% \mathrm{Cl})$ \\
\hline \multicolumn{9}{|l|}{$\begin{array}{l}\text { Repetitivity } \\
\text { (shoulder movements/min) }\end{array}$} \\
\hline Reference $\ddagger$ & 1536 & 179 & 1.0 & 1.0 & 1600 & 14 & 1.0 & 1.0 \\
\hline Low (1-15 movements/min) & 1803 & 239 & 1.2 & $1.1(0.9$ to 1.3$)$ & 1896 & 27 & 1.6 & $1.3(0.7$ to 2.6$)$ \\
\hline High (16-40 movements/min) & 1132 & 204 & 1.7 & $1.5(1.2$ to 1.9$)$ & 1204 & 40 & 3.9 & $3.0(1.5$ to 5.8$)$ \\
\hline \multicolumn{9}{|l|}{ Force requirements } \\
\hline Reference & 1536 & 179 & 1.0 & 1.0 & 1600 & 14 & 1.0 & 1.0 \\
\hline Low $(<10 \%$ of $\mathrm{MVC}) \S$ & 1953 & 293 & 1.3 & $1.2(0.9$ to 1.5$)$ & 2061 & 48 & 2.7 & 1.9 (1.0 to 3.6$)$ \\
\hline High $(\geqslant 10 \%$ of $M V C)$ & 986 & 152 & 1.4 & $1.3(1.0$ to 1.7$)$ & 1045 & 19 & 2.1 & $2.0(1.0$ to 4.2$)$ \\
\hline \multicolumn{9}{|l|}{$\begin{array}{l}\text { Neck flexion } \\
\text { (proportion of task cycle time with } \\
\text { neck flexed }>20^{\circ} \text { ) }\end{array}$} \\
\hline Reference & 1534 & 179 & 1.0 & 1.0 & 1598 & 14 & 1.0 & 1.0 \\
\hline Low $(<66 \%$ of time) & 1733 & 235 & 1.2 & $1.1(0.9$ to 1.4$)$ & 1837 & 28 & 1.8 & $1.4(0.7$ to 2.9$)$ \\
\hline High ( $\geqslant 66 \%$ of time) & 1206 & 210 & 1.6 & $1.4(1.1$ to 1.8$)$ & 1269 & 39 & 3.6 & $2.6(1.3$ to 5.1$)$ \\
\hline \multicolumn{9}{|l|}{$\begin{array}{l}\text { Lack of recovery time } \\
\text { (proportion of task cycle time } \\
\text { without micropauses) }\end{array}$} \\
\hline Reference & 1536 & 179 & 1.0 & 1.0 & 1600 & 14 & 1.0 & 1.0 \\
\hline Low $(<80 \%$ of time) & 476 & 68 & 1.3 & $1.2(0.9$ to 1.6$)$ & 496 & 5 & 1.2 & $1.0(0.4$ to 2.9$)$ \\
\hline High ( $\geqslant 80 \%$ of time) & 2371 & 367 & 1.4 & $1.3(1.0$ to 1.5$)$ & 2518 & 60 & 2.8 & 2.1 (1.1 to 3.9$)$ \\
\hline \multicolumn{9}{|c|}{$\begin{array}{l}\text { *OR, odds ratio. } \\
\text { †Adjustment for individual factors: age, gender, body mass index, pain pressure threshold, intrinsic effort, physical leisure time activity, psychosocial } \\
\text { factors, and level of distress. } \\
\text { †Reference category includes workers with non-repetitive work tasks. } \\
\text { §Maximal voluntary contraction. }\end{array}$} \\
\hline
\end{tabular}

companies reorganised, and the only individual predictor for drop out was young age, reflecting the fact that many jobs in supermarkets, poultry processing plants, postal services, and elsewhere are held youths for short time intervals, while they are preparing forthcoming education or employment in less physically demanding and better paid jobs. A Swedish study also found that drop out was caused by reasons unrelated to exposure and outcome. ${ }^{17}$

To our knowledge, the only other follow up study which benefits from a more objective measurement of physical load (that is, video recordings at the workplace) is the smash study from the Netherlands. ${ }^{4}$ They used regular or prolonged neck pain in the previous 12 months as the outcome, and found that $14.4 \%$ reported that they had neck pain at least once during a total follow up period of three years. We found an annual occurrence of $14.1 \%$ for future onset of neck/shoulder pain with our definition. They found that sitting for more than $95 \%$ of the working time was a risk factor for neck pain and a trend was found for neck flexion for $60-70 \%$ of time and more than $70 \%$ of time. We found comparable increased risk related to neck flexion for more than two thirds of the working time, and our larger study supplied more statistical power. The relation between sitting time and neck pain is explained by a possible relation between prolonged sitting and continuous static load on the neck muscles, but this load was not measured. We assessed a measure for lack of recovery time in the shoulder for more than two seconds, and provide a percentage of working time with no recovery; this proxy

Table 3 Combined physical risk factors for onset of neck/shoulder pain with pressure tenderness (clinical cases) among industrial workers

\begin{tabular}{|c|c|c|c|c|c|}
\hline Combined physical exposure & $n$ & Cases & $\mathrm{OR}_{\text {crude }}^{*}$ & $\mathrm{OR}_{\mathrm{adi}} \dagger(95 \% \mathrm{Cl})$ & $\mathrm{OR}_{\mathrm{inf}} \ddagger(95 \% \mathrm{Cl})$ \\
\hline \multicolumn{6}{|l|}{ Repetition and force } \\
\hline Reference & 1600 & 14 & 1.0 & 1.0 & \\
\hline Low repetition and low force & 1421 & 22 & 1.8 & $1.3(0.6$ to 2.7$)$ & 1.0 \\
\hline High repetition and low force & 638 & 26 & 4.8 & $3.3(1.6$ to 6.9$)$ & $2.4(1.3$ to 4.5$)$ \\
\hline Low repetition and high force & 475 & 5 & 1.2 & $1.3(0.4$ to 3.7$)$ & $1.1(0.4$ to 3.1$)$ \\
\hline High repetition and high force & 566 & 14 & 2.9 & $2.6(1.2$ to 5.9$)$ & $2.2(1.1$ to 4.7$)$ \\
\hline \multicolumn{6}{|c|}{ Repetition and percentage of working time with neck flexed $\geqslant 20^{\circ}$} \\
\hline Reference & 1598 & 14 & 1.0 & 1.0 & \\
\hline Low repetition and low $\%$ of time & 1494 & 18 & 1.4 & $1.2(0.6$ to 2.5$)$ & 1.0 \\
\hline High repetition and low $\%$ of time & 339 & 10 & 3.4 & $2.5(1.0$ to 6.0$)$ & $1.9(0.9$ to 4.6$)$ \\
\hline Low repetition and high \% of time & 402 & 9 & 2.6 & $1.6(0.6$ to 4.1$)$ & $1.2(0.5$ to 3.0$)$ \\
\hline High repetition and high $\%$ of time & 865 & 30 & 4.1 & $3.2(1.6$ to 6.4$)$ & 2.6 (1.4 to 4.8$)$ \\
\hline \multicolumn{6}{|l|}{ Repetition and recovery time } \\
\hline Reference & 1600 & 14 & 1.0 & 1.0 & \\
\hline Low repetition and high recovery & 436 & 4 & 1.0 & $1.0(0.3$ to 3.1$)$ & 1.0 \\
\hline High repetition and high recovery & 60 & 1 & 1.9 & $1.5(0.2$ to 11.9$)$ & $1.4(0.2$ to 13.2$)$ \\
\hline Low repetition and low recovery & 1421 & 23 & 1.9 & $1.4(0.7$ to 2.9$)$ & $1.4(0.5$ to 4.1$)$ \\
\hline High repetition and low recovery & 1091 & 37 & 4,0 & $3.1(1.6$ to 6.0$)$ & $3.0(1.1$ to 8.6$)$ \\
\hline
\end{tabular}

*OR, odds ratio.

†Adjusted for age, gender, body mass index, intrinsic effort, physical leisure time activity, psychosocial risk factors, pain pressure threshold, and level of distress.

$\ddagger$ Exclusion of non-exposed reference group. Same adjustments as in $\dagger$ 
Table 4 Psychosocial risk factors for onset of neck/shoulder pain (symptom cases) and neck/shoulder pain with pressure tenderness (clinical cases)

\begin{tabular}{|c|c|c|c|c|c|}
\hline \multirow[b]{3}{*}{ Risk factor } & \multirow[b]{3}{*}{$n$} & \multicolumn{2}{|c|}{ Symptom cases $(n=636)$} & \multicolumn{2}{|c|}{ Clinical cases $(n=82)$} \\
\hline & & $\mathrm{OR}_{\text {crude }}{ }^{*}$ & $\mathrm{OR}_{\mathrm{adi}} \dagger$ & $\mathrm{OR}_{\text {crude }}$ & $\mathrm{OR}_{\mathrm{adi}}$ \\
\hline & & $(95 \% \mathrm{Cl})$ & $(95 \% \mathrm{Cl})$ & $(95 \% \mathrm{Cl})$ & $(95 \% \mathrm{Cl})$ \\
\hline \multicolumn{6}{|c|}{ Job demands } \\
\hline Low & 2880 & 1.0 & 1.0 & 1.0 & 1.0 \\
\hline High & 1805 & 1.7 (1.5 to 2.0 ) & 1.5 (1.3 to 1.8$)$ & $2.3(1.4$ to 3.5$)$ & 1.7 (1.1 to 2.9 ) \\
\hline \multicolumn{6}{|l|}{ Job control } \\
\hline High & 3329 & 1.0 & 1.0 & 1.0 & 1.0 \\
\hline Low & 1348 & 1.4 (1.2 to 1.7$)$ & $1.2(1.0$ to 1.5$)$ & $1.8(1.1$ to 2.8$)$ & $1.3(0.8$ to 2.1$)$ \\
\hline \multicolumn{6}{|c|}{ Social support } \\
\hline High & 3214 & 1.0 & 1.0 & 1.0 & 1.0 \\
\hline Low & 1216 & 1.1 (0.9 to 1.3$)$ & $1.0(0.9$ to 1.3$)$ & $1.4(0.8$ to 2.2$)$ & $1.3(0.8$ to 2.1$)$ \\
\hline
\end{tabular}

*OR, odds ratio.

†Adjusted for all psychosocial factors (other factors in the table), physical risk factors, and individual factors: age, gender, body mass index, intrinsic effort, physical leisure time activity, and level of distress.

measure for static load was associated with pain and clinical signs as well, especially in combination with high repetition (table 3). We would though prefer terms like "a more continuous load" or "lack of recovery time"implying that static load describes something suitable for laboratory circumstances, where a static load could be simulated for maybe several minutes, but not for hours in a working day. The smash study found increased risk for high quantitative job demands and low coworker support in relation to neck pain. ${ }^{18}$ We only could support a significant contribution of job demands and for future symptoms also for job control, but not for social support. Dividing social support into coworker and supervisor support in our population did not provide more insight.

Our findings that future pain and clinical signs were strongly related to previously having other symptoms indicative of distress or maybe aspects of somatisation adds to similar results for forearm pain, chronic widespread pain, back pain, and shoulder pain. ${ }^{5-7} 1920$

What is neck/shoulder pain?

This study emphasises the multifactorial nature of neck/ shoulder pain. Others have advocated making a distinction between risk factors for neck pain and shoulder pain. We found no support for the risk factors studied here having a differential impact on neck pain and shoulder pain, and as long as the outcomes are diffuse pain, and the exposures are broad and unspecified, such as sitting time, we do not think it is of obvious importance to distinguish. In clinical practice pain complaints from the neck, the shoulder girdle, and part of the shoulder go together. In our data the physical loads were strongly inter-correlated, which diminished our ability to disentangle the effect of each of the physical exposures. Repetitive movements of the shoulder and arm stands out as the most import physical risk factor, but work tasks with high repetition were often characterised by low percentage of recovery time and high percentage of time with neck flexed; this combination of adverse physical factors was also related to rating the work as a job with high demands and low control

Future studies should consider the importance of all the risk factors, and elucidate different risk factors for onset of pain, amplification of pain, development to disorders, and to disability, in more detail. In addition to addressing workplace interventions, much could in our opinion be gained by avoiding misleading terms, ${ }^{6}$ avoiding further somatisation, avoiding unnecessary sick leave, and avoiding everyday pain and aches to be further medicalised. ${ }^{21}$

Table 5 Combined regression model of risk factors for onset of neck/shoulder pain (symptom cases) and neck/shoulder pain with pressure tenderness (clinical cases)

\begin{tabular}{|c|c|c|}
\hline & Symptom cases $(n=636)$ & Clinical cases $(n=82)$ \\
\hline Exposure & Odds ratio $(95 \% \mathrm{Cl})$ & Odds ratio $(95 \%$ Cl) \\
\hline \multicolumn{3}{|l|}{ Combined physical exposure* } \\
\hline Reference category & 1 & 1 \\
\hline Low & $1.1(0.6$ to 1.9$)$ & $1.3(0.3$ to 6.0$)$ \\
\hline Medium & $1.1 \quad(0.9$ to 1.4$)$ & $1.8(0.9$ to 3.6$)$ \\
\hline High & 1.5 (1.2 to 1.9$)$ & $3.2(1.6$ to 6.6$)$ \\
\hline \multicolumn{3}{|l|}{ Job demands } \\
\hline Refence category & 1 & 1 \\
\hline High job demands & 1.5 (1.3 to 1.8$)$ & 2.0 (1.2 to 3.3$)$ \\
\hline \multicolumn{3}{|l|}{ Gender } \\
\hline Male & 1 & 1 \\
\hline Women & $0.9(0.8$ to 1.1$)$ & 1.8 (1.1 to 3.2$)$ \\
\hline \multicolumn{3}{|l|}{ Pain pressure threshold } \\
\hline Reference-high threshold & 1 & 1 \\
\hline Low pain pressure threshold & 1.3 (1.1 to 1.5$)$ & 0.8 (0.5 to 1.3$)$ \\
\hline \multicolumn{3}{|l|}{ Level of distress } \\
\hline Low & 1 & 1 \\
\hline Medium & 1.4 (1.1 to 1.7$)$ & 1.7 (1.0 to 2.9$)$ \\
\hline High & 1.8 (1.4 to 2.5$)$ & $2.8(1.4$ to 5.4$)$ \\
\hline
\end{tabular}

*Physical strain index on the basis of shoulder repetition, force requirements, percentage with neck flexion more than $20^{\circ}$, and percentage of time with lack of recovery. High physical exposure is high level on at least three of the four quantitative measures. 


\section{Authors' affiliations}

J H Andersen, A Kaergaard, U F Jensen, P Frost, Department of Occupational Medicine, Herning Hospital, Denmark

S Mikkelsen, J F Thomsen, Department of Occupational Medicine, Copenhagen County Hospital, Glostrup, Denmark

N Fallentin, National Institute of Occupational Health, Copenhagen, Denmark

J P Bonde, Department of Occupational Medicine, Aarhus University Hospital, Denmark

The study was supported by grants from the Danish Working Environment Fund and the Danish Medical Research Council

\section{REFERENCES}

1 Bernard B, ed. Musculoskeletal disorders and workplace factors. A critical review of epidemiological evidence for work-related musculoskeletal disorders of the neck, upper extremity, and low back. Cincinnati, OH: US Department of Health and Human Services, 1997.

2 Vingård $E$, Nachemson A.Work-related influences on neck and low back pain.In: Nachemson A, Jonsson E, eds. Neck and back pain. The scientific evidence of causes, diagnoses and treatment. Philadelphia: Lippincott Williams \& Williams, 2000:97-126.

3 Ariens GA, van Mechelen W, Bongers PM, et al. Physical risk factors for neck pain. Scand J Work Environ Health 2000;26:7-19.

4 Ariens GA, Bongers PM, Douwes $M$, et al. Are neck flexion, neck rotation, and sitting at work risk factors for neck pain? Results of a prospective cohort study. Occup Environ Med 2001;58:200-7.

5 Miranda H, Viikari-Juntura E, Martikainen R, et al. A prospective study of work related factors and physical exercise as predictors of shoulder pain. Occup Environ Med 2001;58:528-34.

6 Macfarlane GJ, Hunt IM, Silman AJ. Role of mechanical and psychosocial factors in the onset of forearm pain: prospective population based study. BM 2000;321:676-9

7 McBeth J, Macfarlane GJ, Benjamin S, et al. Risk factors for persistent chronic widespread pain: a community-based study. Rheumatology 2001;40:95-101.
8 Andersen JH, Kaergaard A, Frost P, et al. Physical, psychosocial and individual risk factors for neck/shoulder pain with pressure tenderness in the muscles among workers performing monotonous, repetitive work. Spine 2002; 27:660-7.

9 Kaergaard A, Andersen JH. Musculoskeletal disorders of the neck and shoulders among sewing machine operators: prevalence, incidence and prognosis. Occup Environ Med 2000;57:528-34.

10 Karasek R, Theorell T. Healthy work. New York: Basic Books, 1990.

11 Siegrist J, Peter R. Measuring effort-reward imbalance at work: guidelines. Düsseldorff: University of Düsseldorff, 1996.

12 Setterlind SLG. The stress profile: a psychosocial approach to measuring stress. Stress Medicine 1995;11:85-92.

13 Kaergaard A, Andersen JH, Rasmussen K, et al. Identification of neck-shoulder disorders in a 1 year follow-up study. Validation of a questionnaire-based method. Pain 2000;86:305-10.

14 Fallentin N, Juul-Kristensen B, Mikkelsen S, et al. Physical exposure assessment in monotonous repetitive work - the PRIM study. Scand J Work Environ Health 2001;27:21-9.

15 Juul-Kristensen B, Fallentin N, Hansson GA, et al. Force demands during manual and mechanical deboning of poultry estimated by electromyography, force tranducers, observer-based force estimations and electrogoniometer registrations. International Journal of Industrial Ergonomics 2002;29:107-15.

16 Scheike TH, Jensen TK. A discrete survival model with random effects: an application to time to pregnancy. Biometrics 1997;53:318-29.

17 Bildt C, Alfredsson L, Punnett L, et al. Effects of drop out in a longitudinal study of musculoskeletal disorders. Occup Environ Med 2001;58:194-9.

18 Ariëns GAM. Work-related risk factors for neck pain [thesis].Amsterdam: Vrije Universiteit, 2001.

19 Waddell G. The back pain revolution. Edinburgh: Churchill Livingstone, 1998.

20 McBeth J, Macfarlane GJ, Benjamin S, et al. Features of somatization predict the onset of chronic widespread pain. Arthritis Rheum 2001;44:940-6.

21 Hadler NM. Occupational musculoskeletal disorders. Philadelphia: Lippincott Williams \& Wilkins, 1999.

\section{$\mathrm{ECHO}$}

\section{Respiratory physicians rule on fitness to dive}

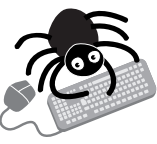

Please visit the Occupational and

Environmental website [www.occenvmed. com] for link to this full article.
- ormal guidelines on deciding respiratory fitness for subaqua diving are available to phy-

- sicians and GPS for the first time from the British Thoracic Society. Diving as a sport is

booming, and doctors will be asked to assess fitness to dive more often and more stringently. They now have ready access to practical evidence based advice and guidance on when to seek specialist opinion. Both evidence and recommendations are graded according to SIGN criteria, and the guidelines will be audited for their usefulness.

The diving environment and its physiological effects pose special risks to divers. Pressure effects, decompression illness, and pulmonary oedema are all direct hazards. Then there are the effects of pre-existing respiratory illness and the potential need to be able to rescue another diver in difficulty. All are brought to bear in assessing fitness to dive.

Essentially, anyone without existing respiratory symptoms or previous lung disease or injury is fit to dive if respiratory examination and spirometric and PEFR measurements show no abnormalities, otherwise they are not. Anyone with respiratory symptoms or previous lung disease or injury is fit to dive if these measurements, plus chest and $x$ ray examination, are normal, unless the condition is one that precludes diving or needs further specialist advice. Such conditions are lung bullae or cysts, previous spontaneous pneumothorax, some types of asthma, COPD, active sarcoidosis or tuberculosis and other serious lung conditions. Whatever the respiratory picture, though, ruling out other conditions that might compromise diver safety- diabetes or epilepsy-is essential.

A Thorax 2003;58:3-13 